\title{
Plasma Fibrinogen Level, Homeostatic Alterations And Nitric Oxide Levels in Chronic Renal Disease
}

\author{
Dr. Roma Rattan ${ }^{1}$,Dr. Manorama Swain ${ }^{3}$,Dr. Srikrushnamahapatra ${ }^{2}$ \\ ${ }^{1}$ Assistant Professor, Department of Biochemistry, S.C.B. Medical College, Cuttack \\ ${ }^{2}$ Professor and H.O.D, Department of Biochemistry, S.C.B. Medical College, Cuttack \\ ${ }^{3}$ Associate Professor, Department of Biochemistry, S.C.B. Medical College, Cuttack
}

\begin{abstract}
:
Background and objectives: Recent studies have elucidated thealterations in hemostatic profile in chronic renal disease. This study aims at evaluating the changes in the hemostatic profile in stage III and IV patients of chronic renal disease. Material and methods: This case-control study included chronic renal failure patients of stagesIII , IV and an equal number of matched healthy volunteers. Serum Urea, Creatinine, plasma fibrinogen, bleeding time, prothrombin time, APTT, platelet count, D-Dimer and nitric oxide were estimated in all the patients.
\end{abstract}

Results: a significantly increase plasma fibrinogen level

\section{Introduction}

Chronic renal disease (CKD) is a worldwide health problem associated with prothrombic tendency and bleeding diathesis [1]. Platelet dysfunction, prolonged bleeding time is the other vascular dysfunctions associated with hyperureamic status of CKD [2]. Thrombosis in glomerular arteries and alterations in platelet count are often observed in CKD. Platelets directly contribute to the disease progression in CKD by causing autoimmune deposition in the glomerular apparatus thus, deranging their filtering ability [3]. The platelet dysfunction in CKD is due to intrinsic abnormalities and endothelial dysfunction of the vascular system. The normal physiological response of platelets such as recruitment, aggregation, adhesion to damaged vascular wall is impaired in CKD [4]. Various studies have suggested the association of platelet dysfunction and coagulation abnormalities in CKD [4, 5]. Hypercoagulopathy, impaired fibrinolytic activity predisposing to a thromboembolic phenomenon is observed in renal diseases [5].The vascular entrée for dialysis in Stage III and IV CKD patients is often affected by thrombosis. Studies reveal upto $60 \%$ of CKD patients with central venous catheter are affected by thrombosis [6]. Altered haemostasis, perioperative bleeding, hypercoagulable state, vascular dysfunction is often found in CKD patients [6,7].

One of the important regulators of hemostasis, vascular endothelial function and renal tubular function is nitric oxide (NO). NO produced in the kidney is responsible for hemostasis, vascular function, sodium excretion and maintenance of arterial blood pressure [7, 8 and 9]. Hence, this study was designed to estimate the Serum Urea, Creatinine, plasma fibrinogen, bleeding time, prothrombin time, APTT, platelet count, D-Dimer and nitric oxide in CKD patients and healthy volunteers. We also aimed to find the association of NO with the above parametersof coagulopathy.

\section{Material and Methods}

This case-control study was conducted in the Department of Biochemistry, SCB Medical College during August 2015 to September 2016. We included stage III and stage IV CKD patients undergoing dialysis in the Department of Nephrology, SCB Medical College. The staging was done as per the estimated glomerular filtration rate. The study included three groups: group-1 included age and sex matched healthy volunteers; group-2 included stage III CKD patients; group-3 included stage IV CKD patients. In each group 50 numbers of individuals were included. All patients on antiplatelet therapy, septicemia, and other vascular or bleeding disorders were excluded. Fasting venous blood samples were collected and plasma was used within two hours for estimation of prothrombin time, activated partial thromboplastin time, fibrinogen level and D.dimer. A complete blood cell count (CBC), hemoglobin levels and Erythrocyte sedimentation rates were also done. All the data is represented as mean \pm standard deviation. The statistical analysis was done by SPSS version 19 . An one way ANOVA was done to compare the data and Pearson's correlation analysis was used to establish the relation between the parameters. A p value $<0.05$ was considered significant.

\section{Results}

The present study included 100 cases of chronic kidney diseases, 50 for stage III and 50 for stage-IV. There were 35 males and 15 females in stage III and 40 males and 10 females in stage IV. In stage III CKD 8 
out of 50 patients, had a plasma D.dimer level less than $250 \mathrm{ng} / \mathrm{ml} .32$ patients had value $250-500 \mathrm{ng} / \mathrm{ml}$ and 4 patients had value in the range of $500-1000 \mathrm{ng} / \mathrm{ml}$. we observed that in stage IV, 6 patients out of $50 \mathrm{had}$ D.dimer level in the range of 250-500 ng/ml. 42patients had 500-1000ng/ml and 2 patients had D.dimer level between 1000-2000ng/ml. Table 1 shows the comparison of the biochemical parameters. We observed significant difference in the plasma fibrinogen levels in the pataients and controls. There was significantly higher level in stage IV CKD pateints. Plasma D- Dimer level was also high in the CKD patients. Plasma nitric acid level was also low in the CKD patients. A significantly lower hemoglobin level, lower RBC, WBC and platelet count was seen in these patients. We observed a significant correlation between the plasma fibrinogen level and nitric oxide level.

Table 1. Comparison of the biochemical parameters

\begin{tabular}{|l|l|l|l|}
\hline Biochemical parameters & Controls & Stage III CKD PATIENTS & STAGE IV CKD PATIENTS \\
\hline $\begin{array}{l}\text { Plasma fibrinogen level } \\
(\mathrm{mg} \%)\end{array}$ & $152 \pm 6.3$ & $268 \pm 5.4^{\mathrm{a}}$ & $374 \pm 5.6^{\mathrm{b}, \mathrm{c}}$ \\
\hline D-Dimer level (ng/ml) & $98.1 \pm 2.2$ & $200 \pm 6.54^{\mathrm{a}}$ & $244 \pm 6.73^{\mathrm{b}, \mathrm{c}}$ \\
\hline Prothrombin time (sec) & 12 & $12.64 \pm 1.66$ & $13.2 \pm 0.9$ \\
\hline $\begin{array}{l}\text { International normalized } \\
\text { ratio (INR) }\end{array}$ & 1.1 & 1.5 & 1.8 \\
\hline $\begin{array}{l}\text { Activated partial } \\
\text { thromboplastin time (APTT) } \\
(\text { sec) }\end{array}$ & 28 & 32 & 38 \\
\hline Platelet count/ $\mu \mathrm{L}$ & $25 \times 10^{4}$ & $15 \times 10^{4 \mathrm{a}}$ & \\
\hline WBC count/ $\mu \mathrm{L}$ & 10,000 & $7,500^{\mathrm{a}}$ & $12 \times 10^{4 \mathrm{~b}, \mathrm{c}}$ \\
\hline RBC count million cell / $\mu \mathrm{L}$ & 5.8 & $5.2^{\mathrm{a}}$ & $7000^{\mathrm{b}, \mathrm{c}}$ \\
\hline Hemoglobin $(\mathrm{g} / \mathrm{dl})$ & 14.8 & $10.6^{\mathrm{a}}$ & $4.5^{\mathrm{b}, \mathrm{c}}$ \\
\hline $\begin{array}{l}\text { Plasma nitric oxide level } \\
(\mu \mathrm{M} / \mathrm{L})\end{array}$ & $18.6 \pm 1.6$ & $24.56 \pm 4.2^{\mathrm{a}}$ & $39.32 \pm 6.8^{\mathrm{b}, \mathrm{c}}$ \\
\hline
\end{tabular}

A depicts a significant difference between stage III CKD patients and controls; $b$ depicts a significant difference between stage IV CKD patients and controls; c depicts a significant difference between stage IV CKD patients and stage III CKD patients.

Table 2: Correlation of plasma nitric oxide with plasma fibrinogen

\begin{tabular}{|l|l|l|}
\hline & Plasma fibrinogen & \\
\hline Plasma nitric oxide level & $\mathrm{R}=-0.568$ & $\mathrm{p}$ value 0.002 \\
\hline
\end{tabular}

\section{Discussions}

The present study revealed a s high plasma fibrinogen and D- dimer level in the CKD patients as compared to controls suggesting a hypercoagulable state in these patients. This finding is in congruence with previous studies [10,11and 12]. We observed a lower platelet, WBC count in the patients [12, 13, 14]. A possible cause for the decrease in cell count count be defective and lowered thrombopoeitic activity [15]. These findings explain the common finding of bleeding diathesis in CKD patients and requirement of monitoring and treatment of coagulation disorders in CKD patients $[16,17]$. We observed the nitric oxide which correlated with the plasma fibrinogen level suggesting an inflammatory state, endothelial dysfunction and vascular complications[18, 19].

\section{Conclusion}

In conclusion we suggest all the patients of chronic kidney disease should be screened for bleeding tendency, coagulation disorders to avoid vascular complications. We recommened further evaluation with genetic and molecular markers to elucidate the cause of vascular complications in CKD.

\section{References}

[1]. Jalal DI, Chorchol M, Targher G. Disorder of homeostasis with chronic. Kidney disease. Semin thromb Hemost. 2010; 36 (1) : 34 40.

[2]. Steiner RW, Coggin C, Carvalha AC, Bleeding time in uremia A useful test to assess clinical bleeding AMJ Hematol 1979; 7: 10717.

[3]. Boceardo P, Remuzzi G, Galbusera M, Platelet dysfunction in renal failure semin thrombo Hemost. 2004; 30(5): 579-89.

[4]. KawD, Malhotra D. Platelet dysfunction and end stage renal disease. Semin Dial 2006: 19(4): 317-22.

[5]. Mehta AB, Hoffbrand AV, Hematological aspect of systemic disease. In Hoffbrand AV, Tuden H, eds. Postgraduate hematology. 5th ed. Oxford; Blackwell, 2005; 971-72.

[6]. Hunt BJ, Grcaves M. Acquired venous thrombosis. In: Hoffbrand AV, Tuden H, eds. Postgraduate Haematology 5th ed. Oxford: Blackwell, 2005. 901.

[7]. Kim SY, Lee SK. Son JS, Han YJ, Song HS. Preoperative assessment of coagulation profiles using a thromboelastography in patients with chronic renal faiure. Korean J Anesthesiol 2002; 43: 407-12. 
[8]. Baylis, C. Arginine, arginine analogs and nitric oxide production in chronic kidney disease. Nat Clin Pract Nephrol 2(4), 209 (2006).

[9]. L., R. \& C., B. Glomerular actions of nitric oxide. Kidney Int 48(1), 20 (1995).

[10]. Bollow A, Gadar AMA. Hurab S, Mitwali A, Alwakeel J. Successful Kidney Trensplantation does not reverse coagulopathy in patients with CRF on either heamodialysis or peritoneal dialysis. Saudi J Kid. Dis Transplant 2007; 18: 177-85.

[11]. Gordge MP, Faint RW, Rylance PB, Irelamd, Lance DA, Neild GA. Plasma D.dimer; a useful marker of fibrin break down in renal failure. Thromb Haemost 1989; 61: 522-25.

[12]. Catena C, Zingarol L, Casacclo D, Sechi LA. Abnormalities of coagulation in hypertensive patients with reduced creatinine clearance AMJ Med 2000; 109: 556-61. Fang J, xia LH, Wei WN, songs J. Coagulation factor vii levels in uremic patients and their influences factors. Zhonggug Shi Yan Xue. 2004; 12: 730-32.

[13]. Horl WH. Thrombocytopathy and blood complication in uremia. Weinkin wo chenscher 2006; 5: 134-50.

[14]. Malyszko J, Malszko JS, Mysliwies M, Buczko W. Haemostasis in chronic renal failure. Annal Academiae Medical Bialostocensis 2007; 50: 127-130

[15]. Guffer U, Bessler H, Matachi T, Zevin D, Levi J. Ojatdetti M Platelet count and thrombopoietic activity in patients with chronic renal failure Nephron 1987; 45: 201-3.

[16]. Mikio T, Fumihiko K, Toshiaki T, Hideo W. Study on hemostasis abnormality in patients with diabetic and

[17]. non diabetic chronic renal failure on maintenance haemdialysis JPDT 2001; 34: 1479-84.

[18]. Butt M, Shafi T, Farooq IK. Effects of Dialysis on bleeding time in chronic renal failure. J Pak Med ASS. 1998; 48 : 242-44.

[19]. Schmidt RJ, Yokota S, Tracy TS, Sorkin MI, Baylis C: Nitric oxide production is low in end-stage renal disease patients on peritoneal dialysis. Am J Physiol 276: F794 -F797, 1999

[20]. Aiello S, Noris M, Todeschini M, Zappella S, Foglieni C, Benigni A, Corna D, Zoja C, Cavallotti D, Remuzzi G: Renal and systemic nitric oxide synthesis in rats with renal mass reduction. Kidney Int 52: 171-181, 1997 